\title{
High-temperature shear strength and hardness of cast lead-free solders
}

\author{
R. Mahmudi ${ }^{1 *}$, A. Maraghi ${ }^{1}$, A. R. Geranmayeh ${ }^{2}$ \\ ${ }^{1}$ School of Metallurgical and Materials Engineering, College of Engineering, University of Tehran, Tehran, Iran \\ ${ }^{2}$ Department of Mechanical Engineering, Faculty of Engineering, South Tehran Branch, Islamic Azad University, \\ Tehran, Iran
}

Received 14 April 2016, received in revised form 14 July 2016, accepted 16 August 2016

\begin{abstract}
This paper compares the shear strength and hardness of the tin-based cast lead-free $\mathrm{Sn}-2 \mathrm{Bi}$, Sn-5Sb, and Sn-9Zn binary solder alloys. This was achieved respectively by the shear punch testing (SPT) and Vickers hardness measurement in the temperature range 298-370 K. The results showed that the shear yield stress (SYS), ultimate shear strength (USS), and hardness $(\mathrm{Hv})$ of all three alloys decrease with increasing test temperature. Among all tested materials, $\mathrm{Sn}-2 \mathrm{Bi}$ showed the highest strength and hardness over the whole testing temperature range. This is ascribed to the strong solid solution effect of $\mathrm{Bi}$ in the $\mathrm{Sn}$ matrix, which is superior to the weak solution hardening and particle strengthening effects of $\mathrm{Sb}$ in $\mathrm{Sn}-5 \mathrm{Sb}$, and particle hardening of Zn in Sn-9Zn.
\end{abstract}

K e y w o r d s: lead-free solder, shear strength, hardness

\section{Introduction}

Lead-free solder alloys have attracted much attention in recent years for their widespread use in the microelectronic packaging industry. This is mainly due to the restrictions imposed on the use of lead-containing alloys, and also to a combination of suitable soldering characteristics and mechanical properties they can offer [1]. Accordingly, several lead-free tin-based alloy systems with different alloying elements such as $\mathrm{Ag}, \mathrm{Bi}, \mathrm{Cu}, \mathrm{In}, \mathrm{Ni}, \mathrm{Sb}$, and $\mathrm{Zn}$ have been developed, and their microstructures, mechanical properties, and creep behaviour have been reported $[2,3]$.

Among the developed lead-free solders, the near-eutectic Sn-Bi alloys with Bi contents of about 57 wt.\% have one of the lowest melting points $\left(139^{\circ} \mathrm{C}\right)$ among all solder alloys [4]. These solders, however, suffer from extensive microstructural coarsening at temperatures near $100^{\circ} \mathrm{C}$ [5]. On the other hand, the much more dilute Sn-2 wt.\%Bi alloy with a melting point of about $229^{\circ} \mathrm{C}$ can be considered as a potential material for lead-free soldering applications [6-8]. Antimony has also been used as the alloying element in the binary $\mathrm{Sn}-\mathrm{Sb}$ systems to provide suitable substi- tutes for the $\mathrm{Sn}-\mathrm{Pb}$ solder alloys $[9,10]$. The $\mathrm{Sn}-5 \mathrm{Sb}$ alloy with a relatively high melting point of $245^{\circ} \mathrm{C}$ has been widely studied for its mechanical properties [11] and creep resistance [12]. It has been reported that antimony atoms in solution [13] and SnSb precipitates [14] are the main sources of strengthening increase deformation resistance and reduce the creep rate of the material. Another suitable alternative to the lead-containing solders used in electronic packaging is the near-eutectic Sn-9Zn alloy, with a low melting temperature of about $198^{\circ} \mathrm{C}$, which is very close to the $186^{\circ} \mathrm{C}$ of the eutectic $\mathrm{Sn}-\mathrm{Pb}$ alloy [15]. Low cost, reasonably good mechanical properties [16], and acceptable creep resistance [17] have been reported for this solder.

Due to the relatively low melting points of the solder alloys, working temperatures correspond to high homologous temperatures, at which softening mechanisms are activated. In such cases, the material resistance to softening becomes important, and thus, they should possess sufficient strength at service temperatures. The strength of the lead-free solders has generally been studied by the conventional tensile test $[18,19]$, and to a lesser extent by the shear testing of the joints made on different substrates [20]. Re-

*Corresponding author: tel.: +98 218208 4137; fax: +98 218800 6076; e-mail address: mahmudi@ut.ac.ir 
cently, however, the high-temperature shear strength of the bulk Zn-Sn [21], Sn-Sb-Ag [22], and Zn-Al-Mg-Sn [23] solders has been studied by the localized shear punch testing (SPT) method. It has been reported that SPT is an efficient method that is capable of providing strength data which are well correlated with those found by the conventional tensile tests [24-26]. This method can be particularly advantageous when the material is available only as small test pieces, or there are difficulties with the machining of samples made of very soft materials such as solder alloys. The present investigation compares the hot shear strength and hardness of three common solder alloys, justifying their difference by considering their microstructures.

\section{Experimental procedure}

\subsection{Materials and processing}

The materials used were Sn-2 wt.\% Bi, Sn-5 wt.\% Sb, and Sn-9 wt.\% Zn binary alloys. They were prepared from high purity $(>99.98 \%)$ tin, bismuth, antimony, and zinc, melted at $100 \mathrm{~K}$ above their melting temperature in an electrical furnace under an inert argon atmosphere and cast into $16 \mathrm{~mm}$ diameter bars. In order to ensure that the slabs had similar initial microstructures, the slabs were homogenized at 0.8 of their melting point $\left(T_{\mathrm{m}}, \mathrm{K}\right)$ for $10 \mathrm{~h}$. From the homogenized bars, $12 \mathrm{~mm} \times 12 \mathrm{~mm} \times 1 \mathrm{~mm}$ test specimen slices were excised by an electro discharge wirecut machine, for the SPT and structural characterization. Optical microscopy was used to examine the microstructural evolution of the materials. The specimens were polished with $0.25 \mu \mathrm{m}$ diamond paste, followed by polishing on a micro cloth without any abrasive. Etching was carried out using a $2 \%$ nitric acid and $98 \%$ alcohol solution at room temperature. X-ray diffraction (XRD) analysis was carried out on selected samples to identify the present phases.

\subsection{Mechanical property measurements}

The strength of the alloys was determined by shear punch testing. The 1-mm thick slices of the materials were ground to a thickness of about $0.7 \mathrm{~mm}$ for the SPT. A shear punch fixture with a $3.175 \mathrm{~mm}$ diameter flat cylindrical punch and $3.225 \mathrm{~mm}$ diameter receiving-hole was used for this experiment. Shear punch tests were performed in the temperature range of $298-370 \mathrm{~K}$ using a screw driven Santam universal testing system equipped with a three-zone split furnace. After locating the specimen in the fixture, the assembly of the specimen and SPT fixture were accommodated by the split furnace, heated to the test temperature and held for $20 \mathrm{~min}$ to establish thermal equilibrium in the testing arrangement before the specimen was deformed by the punch. Tests were run with a load cell of $20 \mathrm{kN}$ capacity and at a constant cross-head speed of $0.25 \mathrm{~mm} \mathrm{~min}^{-1}$. After application of the load, the applied load $P$ was measured automatically as a function of punch displacement; the data were acquired by a computer so as to determine the shear stress $(\tau)$ of the tested materials using the relationship:

$$
\tau=\frac{P}{\pi D t}
$$

where $P$ is the punch load, $t$ is the specimen thickness, and $D$ is the average of the punch and die diameters. Three different samples were tested for each condition, and it was observed that the variation in the measured ultimate shear strength values was less than about $3 \%$.

The same configuration was used for the hot hardness tests, in which a cemented-carbide Vickers indenter was mounted in the holder. A load of $10 \mathrm{~N}$ at an approaching rate of $0.5 \mathrm{~mm} \mathrm{~min}^{-1}$ was applied for a dwell time of $30 \mathrm{~s}$. At least three indentations were made on each sample, and the lengths of the diagonals were quantified by an optical microscope. The average values of these diagonals were used to estimate the hardness values using the following relationship:

$$
\mathrm{Hv}=0.1854 F / d^{2},
$$

where $F$ is the applied load in $\mathrm{N}$ and $d$ is the average diagonal length in $\mathrm{mm}$.

\section{Results and discussion}

The shear deformation behaviour of all three materials was investigated by SPT. Despite the fact that all SPT specimens had similar thicknesses of about $0.7 \mathrm{~mm}$, the punch displacement was normalized to the initial specimen thickness in order to eliminate gage effects. The punching load was converted to shear stress and plotted against the normalized displacement, using Eq. (1). SPT curves of the investigated alloys obtained at different temperatures in the range 298-370 K are shown in Fig. 1. It is evident that similar to tensile stress-strain curves, each of the individual curves exhibits a linear part, after which a deviation from linearity is observed. Further loading of the samples results in the load-instability, at which a maximum is observed in the stress-displacement curves. The deviation point is taken as the shear yield stress (SYS), and the stress corresponding to the maximum point is referred to as the ultimate shear strength (USS).

Regarding the reproducibility of the SPT data, especially for the cast materials, attention must be paid to the impact of the comparable sizes of the 

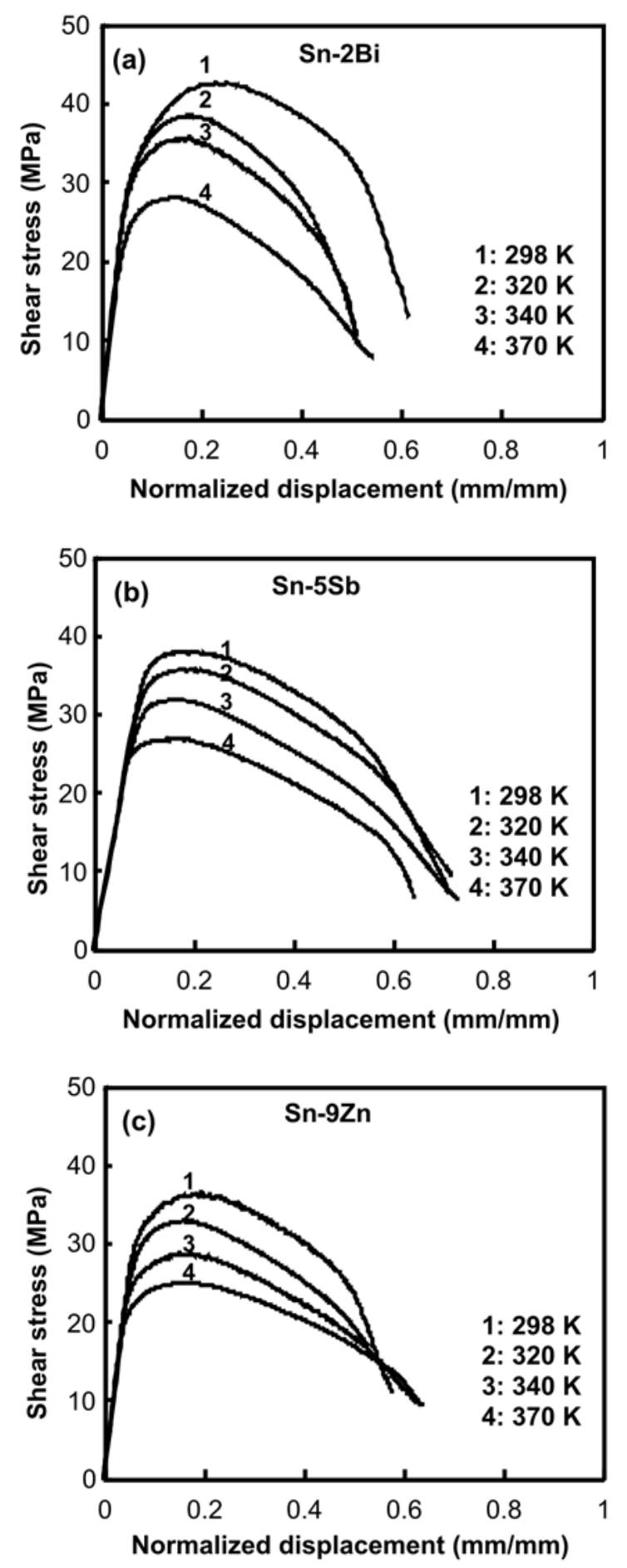

Fig. 1. SPT curves obtained at different temperatures for: (a) Sn-2Bi, (b) Sn-5Sb, and (c) Sn-9Zn.

punch and defects, from one side, and inhomogeneity of the microstructural constituents from the other side. This may cause significant scatter, depending on where the punching is made, and how many particles, grains, and other constituents contribute to the obtained load-displacement data. The same is true for
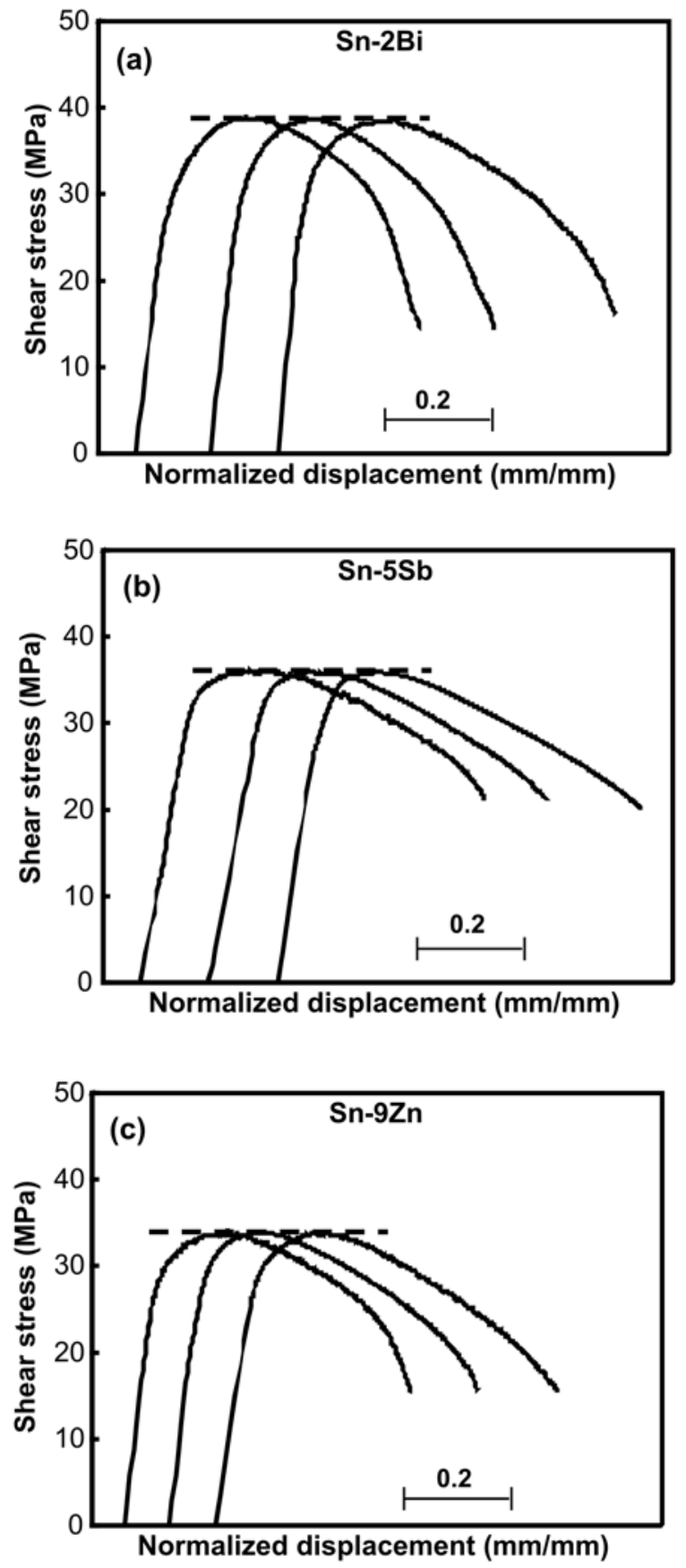

Fig. 2. Shear stress-normalized displacement curves, showing the reproducibility of the results obtained at $320 \mathrm{~K}$ for all three tested materials: (a) Sn-2Bi, (b) Sn-5Sb, and (c) Sn-9Zn.

the microstructural inhomogeneities and defects which may be located beneath the punch, affecting the resistance of the material to punching [27]. In the present work, however, at least three separate samples were tested and the obtained flow curves were very similar in terms of SYS and USS values, as shown in Fig. 2 for all alloys tested at $320 \mathrm{~K}$. This may be indicative 

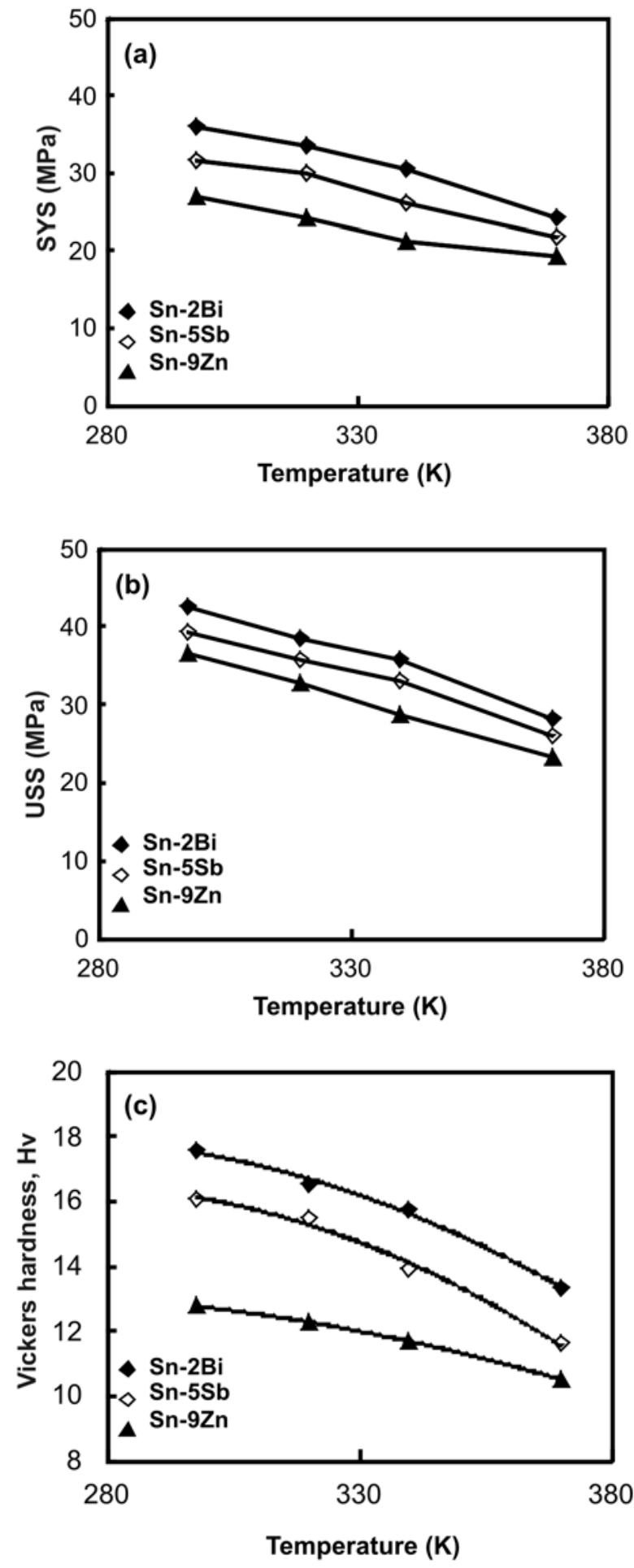

Fig. 3. Variation of: (a) SYS, (b) USS, and (c) Vickers hardness of the alloys with test temperature.

of the fact that due to the relatively high solidification rate, a refined microstructure has been resulted, and hence the SPT data exhibit a high level of reliability. Therefore, SPT can be regarded as a useful tool for investigating the mechanical properties of the present lead-free solder alloys at various temperatures.

In all of the tested materials, increasing the test temperature from 298 to $370 \mathrm{~K}$ results in a significant softening, as indicated by the lower levels of the SPT curves at higher temperatures (Fig. 1). Variations in both SYS and USS values with test temperature are summarized in Figs. 3a and b, respectively. It is evident that the highest SYS and USS values at all test temperatures belong to the $\mathrm{Sn}-2 \mathrm{Bi}$ alloy and the lowest to the Sn-9Zn alloy, those of the Sn-5Sb lying in between. The same order has been previously reported for the creep resistance of the same alloys determined by shear punch creep [28], and indentation and impression creep testing methods [29]. It is worth comparing the present results with those reported for other solder materials in the literature. The USS values of a Sn-1.7Sb-1.5Ag alloy in the temperature range of 298$373 \mathrm{~K}$ have been found to be in the range $18-30 \mathrm{MPa}$, which are lower than those obtained in the present study [22]. Nevertheless, the reported 70 and $48 \mathrm{MPa}$ USS values of the high-temperature lead-free Zn-20Sn obtained, respectively, at 298 and $385 \mathrm{~K}$ [21], are much higher than the corresponding USS values of about 44 and $27 \mathrm{MPa}$, found for the $\mathrm{Sn}-2 \mathrm{Bi}$ in the present work. The temperature dependence of the Vickers hardness $(\mathrm{Hv})$ values for the investigated alloys is plotted in Fig. 3c. It can be inferred that the variations in hardness values follow the same patterns as those already observed for the USS and SYS in Figs. 3a and b, respectively.

Different shear flow behaviour of the tested materials can be ascribed to their respective microstructures shown in Fig. 4. To identify the type of phases present in the microstructures of the tested alloys, XRD analysis was employed, and the results are shown in Fig. 5. As can be observed, in the spectrum of the Sn-9Zn alloy pure zinc is the only phase present in the $\mathrm{Sn}$ matrix as indicated by peaks at $2 \theta=36.3^{\circ}$ and $2 \theta=39.0^{\circ}$. For Sn-5Sb, a weak peak at $2 \theta=$ $29.1^{\circ}$ confirms the presence of $\mathrm{SnSb}$ particles. There is, however, no distinct Bi phase present in the $\mathrm{Sn}-2 \mathrm{Bi}$ alloy pattern, implying that the Bi content of the alloy has mainly remained in solid solution. Back to the microstructures, the micrograph of the Sn-9Zn alloy, shown in Fig. 4a consists of Sn matrix and Zn-rich phase in the form of both fine particles and some relatively coarse needle-shaped precipitates. Therefore, particle hardening is the main strengthening mechanism which enhances the strength of the material as compared to pure tin. For the Sn-5Sb alloy, a rather coarse equiaxed grain structure with an average grain size of about $280 \mu \mathrm{m}$ has been achieved, as depicted in Fig. 4b. This is a recrystallized structure with a low volume fraction of $\mathrm{SnSb}$ intermetallic particles at the grain boundaries. These particles provide some particle strengthening, which is accompanied by some 

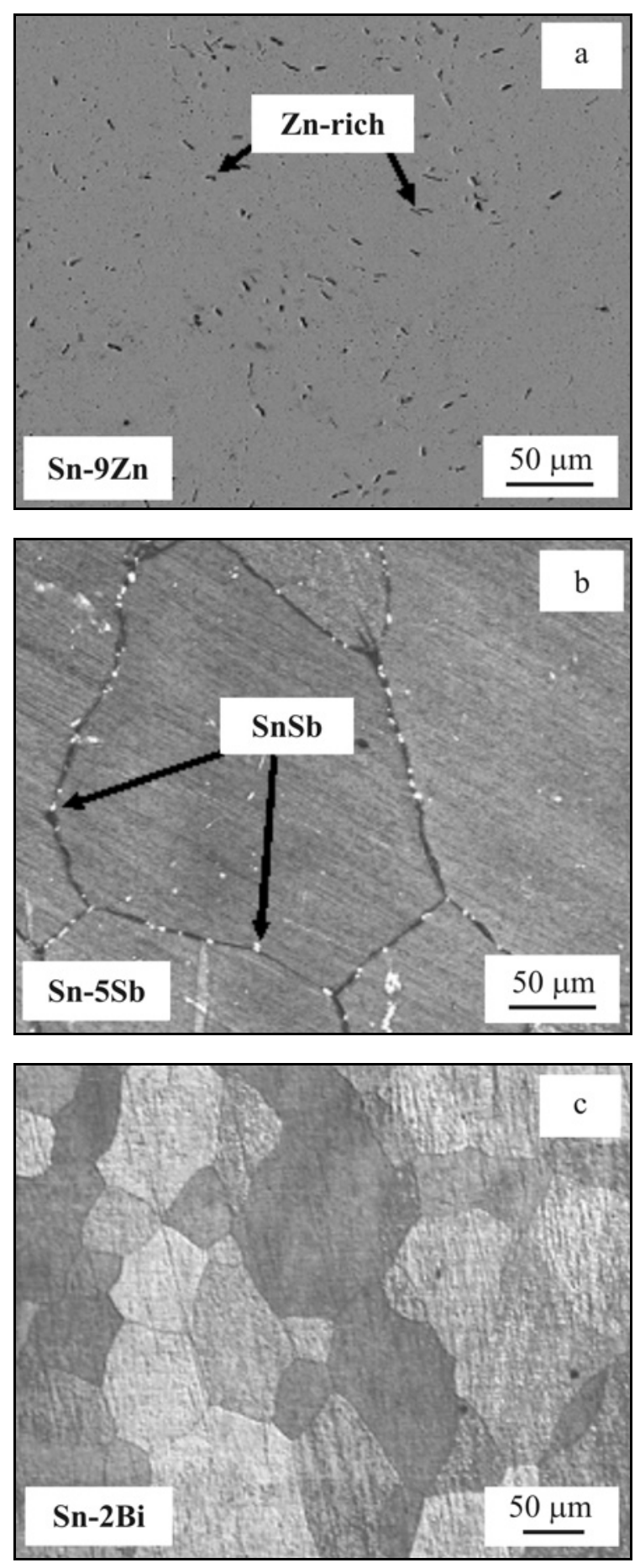

Fig. 4. Optical micrographs of the materials.

solute hardening of $\mathrm{Sb}$ in $\mathrm{Sn}$ to enhance the shear strength of the material [12]. The Sn-2Bi alloy, with the highest shear strength among all tested materials, exhibited a recrystallized grain structure without any initial dendritic structure (Fig. 4c).

The superior strength of the Bi-containing alloy can be ascribed to the strong solid solution strengthening effect of $\mathrm{Bi}$ in the Sn matrix. According to the

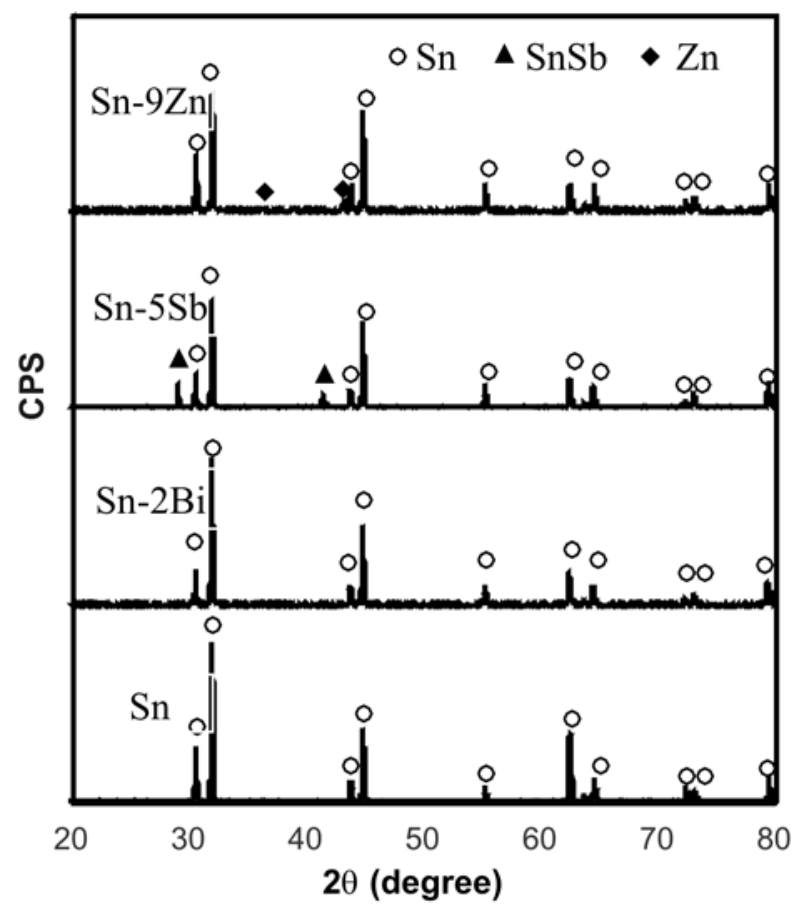

Fig. 5. XRD patterns of pure Sn and the tested materials.

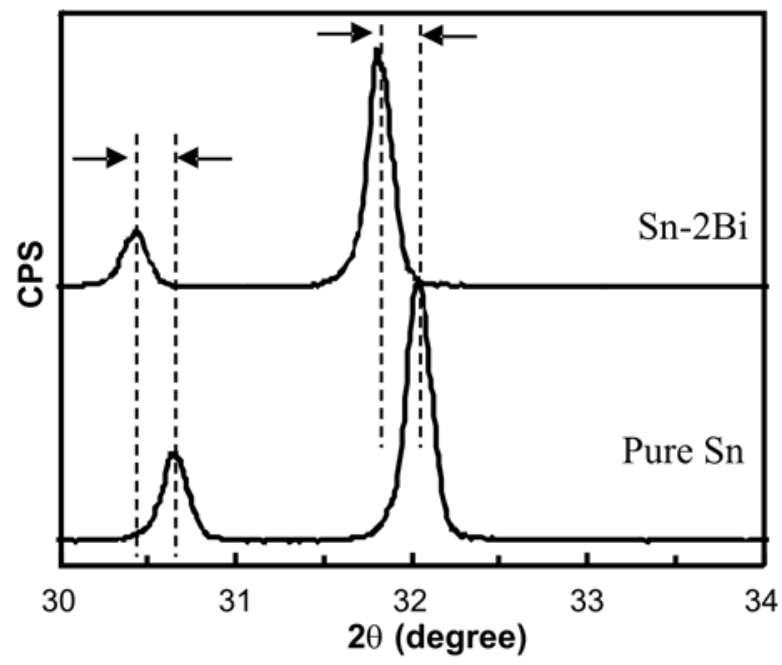

Fig. 6. An enlarged view of the XRD patterns of pure $\mathrm{Sn}$ and $\mathrm{Sn}-2 \mathrm{Bi}$, showing a shift in the $\beta$-Sn peaks from $30.7^{\circ}$ and $32.0^{\circ}$ in pure Sn to $30.5^{\circ}$ and $31.8^{\circ}$ in the $\mathrm{Bi}-$ containing alloy.

Sn-Bi binary phase diagram, the solubility limit of $\mathrm{Bi}$ in $\mathrm{Sn}$ is approximately $21 \mathrm{wt} . \%$ at $139^{\circ} \mathrm{C}$, which reduces to above $2 \mathrm{wt} . \%$ at room temperature [30]. In the current study, with the $\mathrm{Bi}$ content of $2 \mathrm{wt. \%}$, it is likely that $\mathrm{Bi}$ remains in solid solution, resulting in improved strength of the material at both room and elevated temperatures. This can be verified by examining the enlarged XRD patterns of pure Sn and Sn- 
$-2 \mathrm{Bi}$ alloys, as shown in Fig. 6 . The patterns in the range $30^{\circ}$ to $34^{\circ}$ indicate a shift in the $\beta$-Sn peak from $30.7^{\circ}$ and $32.0^{\circ}$ in pure Sn to $30.5^{\circ}$ and $31.8^{\circ}$ in the Bi-containing alloy. The observed shifts in the positions of the Sn diffraction lines are believed to be caused by the dissolution of $\mathrm{Bi}$ in the $\mathrm{Sn}$ matrix [31]. Similar shifts in the XRD peaks have been reported after the introduction of $1.5 \mathrm{wt} . \% \mathrm{Bi}$ into the $\mathrm{Sn}-5 \mathrm{Sb}$ alloy, increasing the indentation creep resistance of the Bi-bearing alloy [32].

\section{Conclusions}

The shear strength and hardness of the three common lead-free Sn-2Bi, Sn-5Sb, and Sn-9Zn solder alloys were respectively tested by the shear punch and Vickers indentation method in the temperature range of $298-370 \mathrm{~K}$. The initial microstructure of Sn-9Zn consisted of Zn-rich particles in the Sn matrix, while that of Sn-5Sb contained sparse SnSb particles, mainly at grain boundaries. The Sn-2Bi alloy showed an equiaxed microstructure with no Bi-rich particles. Among the materials tested, Sn-2Bi had the highest shear strength and hardness, followed by Sn-5Sb and Sn-9Zn over the whole range of test temperatures. The higher strength and hardness of the Sn-2Bi alloy can be attributed to the strong solid solution hardening effects of $\mathrm{Bi}$ in $\mathrm{Sn}$ matrix. The $\mathrm{SnSb}$ particles in $\mathrm{Sn}-5 \mathrm{Sb}$ and Zn-rich phase in Sn-9Zn were not able to compete with the solid solution hardening effect of $\mathrm{Bi}$ in the Sn-2Bi alloy in enhancing the strength and hardness of the materials.

\section{References}

[1] Hong, W. S., Kim, A. Y.: Mater. Trans., 56, 2015, p. 1002. doi:10.2320/matertrans.MI201420

[2] Drápala, J., Kozelková, R., Burkovič, R., Smetana, B., Dudek, R., Lasek, S., Urbánek, J., Dušek, K., Hájek, M.: Kovove Mater., 47, 2009, p. 283.

[3] Chen, Z. H., Bao, X. D., Huang, Z. J., Wang, G., Zhu, X. B., Sun, Y. F.: Kovove Mater., 53, 2015, p. 79. doi:10.4149/km_2015_2_79

[4] McCormack, M., Jin, S., Kammlott, G. W.: Appl. Phys. Lett., 64, 1994, p. 580. doi:10.1063/1.111114

[5] Palmer, M. A., Wainwright, K., Fok, L. C., Jones, B.: JOM, 54, 2002, p. 41. doi:10.1007/BF02701849

[6] Mahmudi, R., Geranmayeh, A. R., Mahmoodi, S. R., Khalatbari, A.: J. Mater. Sci.: Mater. Electron., 18, 2007, p. 1071. doi:10.1007/s10854-007-9124-9

[7] Mitlin, D., Raeder, C. H., Messler, R. W.: Metall. Mater. Trans. A, 30, 1999, p. 115. doi:10.1007/s11661-999-0199-1

[8] Mahmudi, R., Geranmayeh, A. R., Salehi, M., Pirayesh, H.: J. Mater. Sci.: Mater. Electron., 21, 2010, p. 262 . doi:10.1007/s10854-009-9903-6
[9] Mahmudi, R., Geranmayeh, A. R., Bakherad, M., Allami, M.: Mater. Sci. Eng. A, 457, 2007, p. 173. doi:10.1016/j.msea.2007.01.060

[10] El-Daly, A. A, Fawzy, A., Mohamad, A. Z., ElTaher, A. M.: J. Alloys Compd., 509, 2011, p. 4574. doi:10.1016/j.jallcom.2011.01.109

[11] Esfandyarpour, M. J., Mahmudi, R.: Mater. Sci. Eng. A, 530, 2011, p. 402. doi:10.1016/j.msea.2011.09.103

[12] Geranmayeh, A. R., Mahmudi, R.: J. Mater. Sci., 40, 2005, p. 3361. doi:10.1007/s10853-005-0421-5

[13] Murty, K. L., Haggag, F. M., Mahidhara, R. K.: J. Electron. Mater., 26, 1997, p. 839. doi:10.1007/s11664-997-0260-z

[14] McCabe, R. J., Fine, M. E.: Metall. Mater. Trans. A, 33, 2002, p. 1531. doi:10.1007/s11661-002-0075-8

[15] McCormack, M., Jin, S., Chen, H. S.: J. Electron. Mater., 23, 1994, p. 687. doi:10.1007/BF02653357

[16] Abtew, M., Selvaduray, G.: Mater. Sci. Eng., R27, 2000, p. 95. doi:10.1016/S0927-796X(00)00010-3

[17] Mahmudi, R., Geranmayeh, A. R., Noori, H., Jahangiri, N., Khanbareh, H.: Mater. Sci. Eng. A, 487, 2008, p. 20. doi:10.1016/j.msea.2007.09.050

[18] Cheng, F., Gao, F., Wang, Y., Wu, Y., Ma, Z., Yang, J.: Microelectron. Reliab., 52, 2012, p. 579. doi:10.1016/j.microrel.2011.10.003

[19] El-Daly, A. A., Hammad, A. E., Fawzy, A., Nasrallah, D. A.: Mater. Des., 43, 2013, p. 40. doi:10.1016/i.matdes.2012.06.058

[20] Takahashi, T., Komatsu, S., Nishikawa, H., Takemoto, T.: J. Electron. Mater., 39, 2010, p. 1241. doi:10.1007/s11664-010-1233-1

[21] Mahmudi, R., Eslami, M.: J. Mater. Sci.: Mater. Electron., 22, 2011, p. 1168. doi:10.1007/s10854-010-0279-4

[22] Geranmayeh, A. R., Mahmudi, R., Kangooie, M.: Mater. Sci. Eng. A, 528, 2011, p. 3967. doi:10.1016/j.msea.2011.02.034

[23] Mahmudi, R., Farasheh, D.: Microelectron. Reliab., 54, 2014, p. 1592. doi:10.1016/j.microrel.2014.03.008

[24] Guduru, R. K., Darling, K. A., Kishore, R., Scattergood, R. O., Koch, C. C., Murty, K. L.: Mater. Sci. Eng. A, 395, 2005, p. 307. doi:10.1016/j.msea.2004.12.048

[25] Mahmudi, R., Sadeghi, M.: J. Mater. Eng. Perform., 22, 2013, p. 433. doi:10.1007/s11665-012-0256-6

[26] Masoudpanah, S. M., Mahmudi, R., Langdon, T. G.: Kovove Mater., 49, 2011, p. 43. doi:10.4149/km 2011143

[27] Mahmudi, R., Alibbabaie, S.: Mater. Sci. Eng. A, 559, 2013, p. 421. doi:10.1016/i.msea.2012.08.121

[28] Mahmudi, R., Maraghi, A.: Mater. Sci. Eng. A, 599, 2014, p. 180. doi:10.1016/j.msea.2014.01.082

[29] Mahmudi, R., Geranmayeh, A. R.: Int. J. Mat. Res., 101, 2010, p. 271. doi:10.3139/146.110266

[30] Okamoto, H.: Alloy Phase Diagrams. Materials Park, ASM International 1990

[31] Cullity, B. D.: Elements of X-Ray Diffraction. Boston, Addison-Wesley Publishing Company, Inc. 1956.

[32] Geranmayeh, A. R., Mahmudi, R., Khalatbari, F., Kashi, N., Nayyeri, G.: J. Electron. Mater., 43, 2014, p. 717. doi:10.1007/s11664-013-2956-6 